\title{
BEHAVIOUR AND MOOD CYCLES APPARENTLY RELATED TO PARATHYROID DEFICIENCY
}

\author{
BY \\ C. P. RICHTER, W. M. HONEYMAN,* and H. HUNTER \\ From the Psychobiological Laboratory, The Henry Phipps Psychiatric Clinic, The Johns \\ Hopkins Hospital, Baltimore
}

(Received 4TH August, 1939)

INCREASING interest in the cyclic behaviour of man and animals has been evidenced in recent years, especially in so far as these cyclic changes are related to glandular disturbances.

In studies of the spontaneous activity of rats the following cycles have been observed : a 4-5-day cycle associated with ovulation (Wang, 1923); a 14-day cycle after section of the pituitary stalk (Richter, 1933) ; a 15-20-day cycle after parathyroidectomy (Richter and Eckert, 1937); a 25-35-day cycle after thyroidectomy (Richter, 1933) ; and a 100-day cycle after removal of one ovary and all except a small part of the other ovary (Richter, 1927). Hitherto, in other animals and in humans the only cycles definitely known to depend on endocrine glands were the ovulation and menstrual cycles. In humans with pathological disturbances we know of several other cycles, but we have no knowledge regarding their origin : (1) the morning-evening variations in mood seen particularly in depressions ; (2) a 2-day cycle of alternating good and bad days of behaviour and sleep found in manic-depressive patients (Richter, 1938) ; (3) a 4-6-day cycle manifested in sleep (Richter, 1934); and (4) a 9-11-day cycle manifested in attacks of gastric pain (Levine and Richter, 1935).

A cycle of approximately 40 days' duration associated with parathyroid deficiency has now been observed in a parathyroidectomized monkey, and a cycle of about the same length of time has been observed in a patient with a parathyroid deficiency.

\section{Cyclic Behaviour in a Parathyroidectomized Monkey}

The two pairs of parathyroid glands were removed from a male Rhesus macaque which for one month had been kept on a low-calcium diet. Tetany appeared in the hands and arms and the animal assumed peculiar postures,

* Commonwealth Fund Fellow. 
particularly of the hind legs. Blood calcium dropped to $7.0 \mathrm{mg}$. per 100 c.c. ; blood phosphorus increased to $8.6 \mathrm{mg}$. per 100 c.c. After one month and a half the monkey was given access to water and a 2.4 per cent. calcium solution in separate graduated inverted bottles of the same type as those used for rats. The intake from each bottle was measured daily. It was found that parathyroidectomy had produced a marked calcium lactate appetite in the monkey, just as it did in rats (Richter and Eckert, 1939). The animal ingested large amounts daily, as much as 140 c.c. per day, with the result that the blood calcium increased to a higher level $(11.2 \mathrm{mg}$. per 100 c.c.) and the phosphorus decreased to $2.95 \mathrm{mg}$. per 100 c.c.

Of particular interest to us was the fact that the calcium lactate intake curve showed regular cycles of approximately 40 days' duration. Fig. 1,

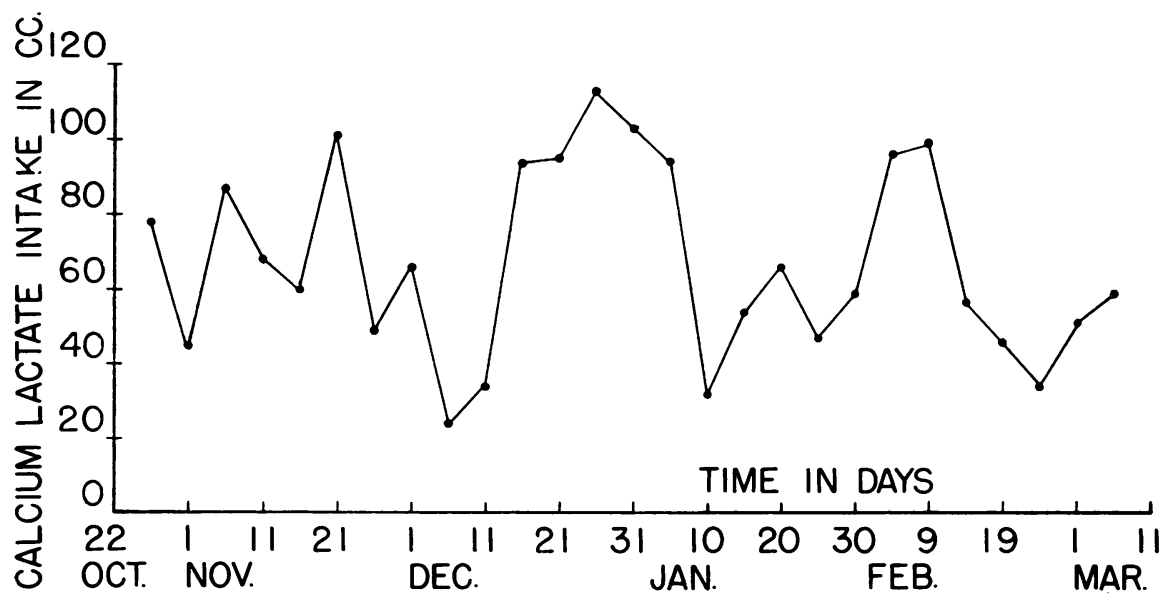

Fig. 1.-Chart of a parathyroidectomized monkey, showing cyclical variations in the daily intake of a 2.4 per cent. calcium lactate solution. The intake of tap water, to which the monkey was also given access, is not shown.

which gives the calcium lactate intake in 10-day averages over a period of 140 days, shows three very clear-cut and regular cycles. No observations were made on other phases of this animal's behaviour. Two other monkeys, parathyroidectomized at the same time, showed similar but less regular cycles.

\section{Cyclic Behaviour in a Patient with Parathyroid Deficiency}

The patient, a 56-year-old female school-teacher, came to the Phipps Clinic in May 1938 complaining of restlessness, depression, muscular cramps, and diarrhœa. Her illness had started 1 month previously, immediately after she had suffered a severe shock and had fallen unconscious as a result of the explosion of an ammonia tank and inhalation of the fumes. She began to sleep poorly, had no appetite, and could not concentrate ; she frequently had suicidal thoughts. 
She gave a history of two previous depressions, one in 1924 which lasted only a few months and one in 1930 at the menopause which lasted about two years. At this time she received X-ray treatments for artificial induction of the menopause. After 1932 she had several depressive spells which lasted only a few weeks, at which time she appeared to benefit from sex hormone treatment.

After the patient had been in the clinic for more than 2 months, the symptoms of parathyroid deficiency which had been present to some degree during this time became prominent. Towards the end of her third month in the clinic, she showed a fine tremor of the hands, fibrillary twitchings of the arm muscles, and the Chvostek and Trousseau tests were positive. She had a low blood calcium (5.8 mg. per 100 c.c.) and a high blood phosphorus (as high as $8.7 \mathrm{mg}$. per 100 c.c.). On admission her vision was poor and later it became increasingly deficient, due to cataracts which formed in both eyes. X-rays showed a marked and uniform degree of decalcification of the bones.

At the end of the third month she was started on calcium therapy and at first given a variety of calcium compounds - calcium lactate, gluconate, and chloride. Later we attempted to repeat an observation made on rats and monkeys by leaving a 2 per cent. calcium lactate solution constantly within her reach with instructions to drink as much as she wanted. Almost from the beginning she drank approximately 1 litre, or $20 \mathrm{gm}$., of the calcium lactate per day; however, contrary to our orders she limited the intake to that amount. Since the intake of the calcium lactate solution was not permitted to vary with changes in calcium appetite as it was in the animals, we could not determine whether it also showed cyclical variations. The patient also received 1 c.c. per day of A. T. 10* (Dihydrotachysterol) for several 4-5-day periods during the course of the calcium therapy.

We gave her calcium in the form of the lactate solution, since parathyroidectomized rats consistently showed a greater preference for calcium lactate and also thrived on it. Recently Wilson (1938) reported that calcium lactate when given in solution is more effective in parathyroid tetany than any of the other calcium compounds given either in solution or in crystalline form. Within 4 weeks the patient's blood calcium increased to $10.3 \mathrm{mg}$. per 100 c.c. and her phosphorus decreased to $5.6 \mathrm{mg}$. per 100 c.c. Her blood-clotting time returned to a more normal level and operations were performed for the removal of the cataracts. She was discharged in January showing a marked improvement in behaviour and a return to almost normal mood.

During the three-month period before the calcium therapy was started, the patient's behaviour showed two cycles of approximately 40 days' duration. After the calcium therapy was started, there was almost no tendency toward cyclical behaviour. Fig. 2 shows a part of the patient's behaviour chart. Markings characteristic of normal behaviour are shown at the top and markings characteristic of depressed behaviour are shown at the bottom. During her first 3 weeks after her admission, from 29th May to 20th June, the patient's behaviour was characterized by preoccupation, sadness, a slow and hesitant manner, irritability, indifference to ward activities, and unwillingness to 


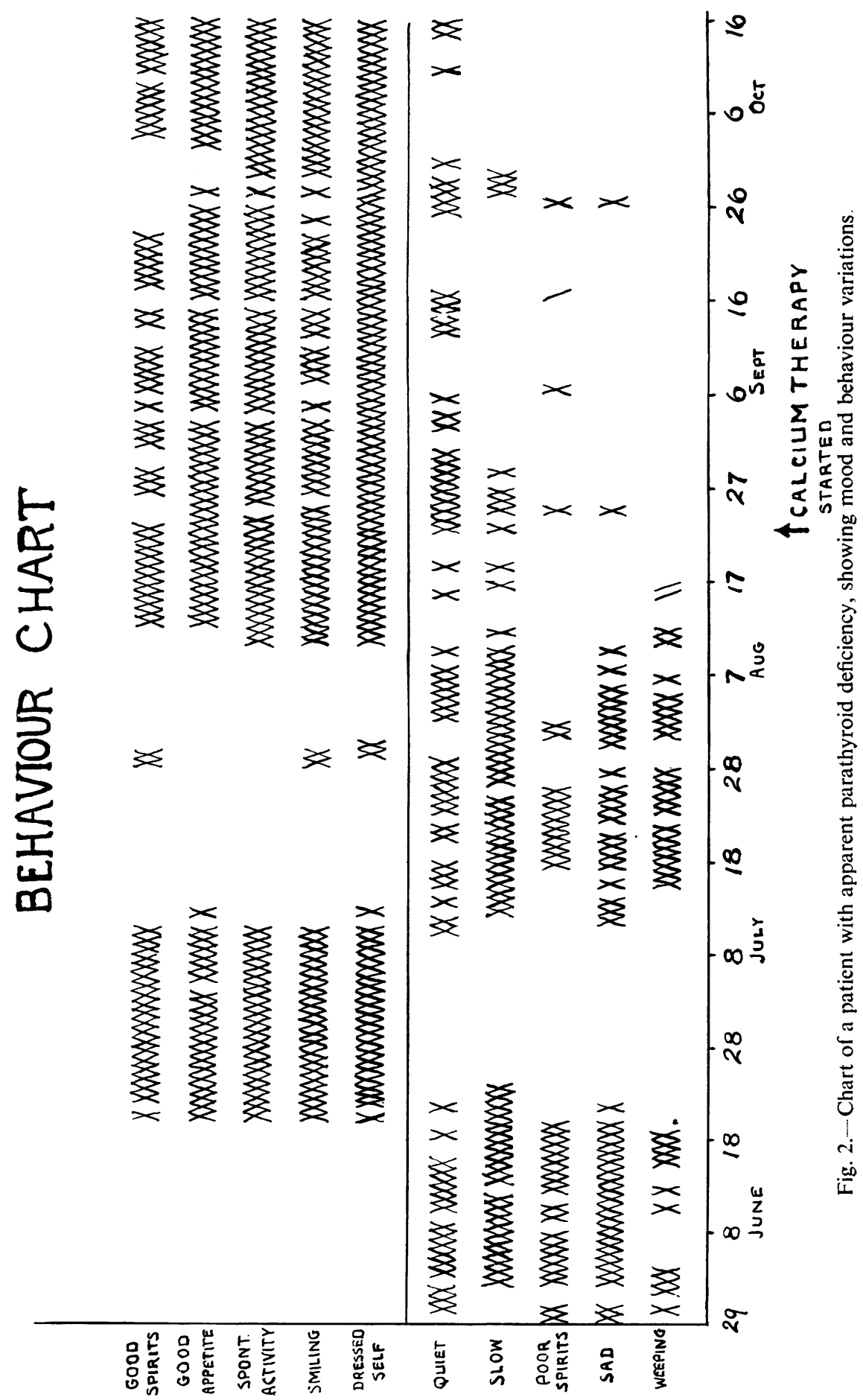


co-operate. She was very quiet except for occasional evidences of bad temper ; she had only a fair appetite. She had to be dressed by the nurse because of her slowness and indifference. A few excerpts from the nurse's notes for 3rd June, 7 days after her admission, shows the character of the patient's behaviour during this phase :

"Patient got up, assisted by nurse, and walked slowly to bathroom as if in pain ; nurse had to help her dress ; she complained that her muscles felt so stiff. . . . She would stop and stare into space as if she didn't know what to do next. Walked up and down corridor looking at her feet, and grins foolishly. Seemed to lapse in memory at times. 'Sometimes I think I'm not anybody.' 'You must tell me what to do. I can't seem to think.' After supper did not enter into conversation or games with other patients. Said she would like to drown herself in the tub. Was in very low spirits, wore a frown on face all evening. Retired saying, 'I wish I would smother and not wake up." "

Seventeen days later, on 20th June, there was an abrupt upswing, a remarkable change in behaviour, characterized by a pleasant humour and a good appetite ; the patient was smiling and co-operative, interested in ward activities, and was able to dress herself. The nurse's notes for this period describe her cheerfulness and normal behaviour :

" Up early, greeting others pleasantly ; needed little assistance in dressing. Seemed in good spirits, laughing and joking, and ate very well. Took an active part in games at gym. Walked about with much more pep. 'I never knew I could feel so low and then come up again." "'

After three weeks of this marked improvement, the patient relapsed and there was an immediate downswing, as can be seen on the behaviour chart, from 11th July to 10th August. The patient became moody, irritable, and unco-operative, with behaviour similar to that during her first 3 weeks. The nurse's notes are typical as for the first period.

This part of the cycle continued for about 4 weeks, when again there was a marked change for the better around 10th August. The patient showed normal behaviour, as can be seen on the chart, with only a few sporadic markings below. On 23rd August the patient was started on calcium therapy. At the end of 3 weeks, when the patient was expected to show a drop in mood according to the previous cycles, no change in behaviour was apparent. Her appetite was good and she showed fairly normal mood and behaviour, except for a slight lapse which occurred in September. This minor drop in mood and behaviour came about a week later than was expected, but was not marked in intensity, and the patient showed almost normal behaviour until her departure in January.

The basis for this illness was never determined. The ammonia explosion may have greatly exaggerated an already existent parathyroid deficiency, or the ammonia fumes may have actually produced the parathyroid deficiency.* MacCallum and Voegtlin (1909), in their experiments with calcium tetany in

* The medical aspects of this case will be discussed in detail in another paper by Dr. Howard and Dr. Emerson of the Endocrine Clinic of the Johns Hopkins Hospital. 
parathyroidectomized animals, first mentioned the existence of an increased ammonia output in the urine and the increase in ammonia in the blood. Carlson and Jacobson (1911) substantiated these results, but were able to offer no proof of any ætiological relationship between the ammonia content of the blood and parathyroid tetanyl.

\section{Discussion}

The mechanism involved in the production of cycles by removal of the various endocrine glands still remains undetermined. From our experience with cyclic phenomena in rats we have concluded that the manifestation of any marked cyclic changes indicates a disturbance in some part of the endocrine system. In the well-functioning normal individual the various cycles existing in the different organs of the body become so perfectly fused that no cycle appears. However, disturbance in any one gland may release a cycle in another, and thus the pattern is upset and a new rhythm is established which shows itself in the behaviour as a phenomenon not ordinarily present. This dependence of the cyclical changes on the interrelationship of the various glands is brought out clearly in a recent paper by Horwitz and Harris (1936) on a psychosis associated with menstruation. Thyroid treatment not only caused the cycles to disappear but also brought about complete recovery from the psychotic symptoms.

McCullagh and Kearns (1935) have observed recurrent acute attacks of tetany in parathyroid deficient patients immediately preceding and during menstrual periods. For further evidence of the close relationship between tetany and the ovaries, they state that in 176 cases of tetany only nine were men; and that Boothby, Haines, and Pemberton (1931) found only one in 88 cases of tetany. They state also that recurrent attacks of tetany were never observed in women who had passed the menopause. The fact that our patient passed the menopause 2 years before her attacks started would indicate that they could not have depended on cyclic changes in the ovaries, unless we are to assume that such cycles persist postmenopausically. That the cyclic variations brought out by parathyroid disturbances have a duration of approximately 40 days in monkeys and in the human studied and only a 15-20-day duration in rats is not inconsistent with our knowledge of the difference in other organic cycles in these three species. Thus, in the rat the cstrous cycle had only a 4-5-day duration, while in monkeys and humans it averages 28 days. With more knowledge regarding the cycles in different species, it may be possible to determine some general underlying principle upon which the frequency of the cycles depends.

The fact that regular cycles of behaviour have been exhibited in rats and monkeys with disturbed glandular systems and, more particularly, the cycles mentioned above in parathyroidectomized animals would make it seem likely that the cyclical changes observed in this patient were definitely connected with the parathyroid deficiency. Moreover, this is in part substantiated by the fact 
that with the calcium therapy there was almost complete disappearance of the cyclical variations and the abnormal mood changes. Also, the fact that this patient had passed the menopause may have contributed to the production of these cycles.

A suggestion of similar cyclic behaviour is also found in one of two cases of psychosis in tetany described by Knospe (1938). Following operation for exophthalmic goitre the patient developed parathyroid insufficiency and went through two phases with anxiety, hallucinations, and overactivity, each lasting about 4 weeks and separated by a more lucid interval of about 2 weeks during which she became amenable and gained insight.

It may be pointed out that in the animal suffering from parathyroidectomy the cycles were shown in an increased appetite for calcium ; in the patient these cycles occurred only when calcium was denied and cleared up on calcium therapy.

We believe that a search of the records of patients with parathyroid and other glandular disturbances may reveal similar cases evidencing cyclic behaviour.

\section{Summary}

Three parathyroidectomized monkeys kept on a low-calcium diet drank large amounts of a 2.4 per cent. calcium lactate solution, thereby alleviating their symptoms of insufficiency. Their intake of calcium lactate solution showed fairly regular cycles averaging 40 days in length.

A woman 56 years of age suffering from a parathyroid deficiency showed quite regular cyclic variations in mood and behaviour with a duration of approximately 40 days. For the first half of each cycle she was depressed and slow ; and for the second half she was fairly normal. After calcium therapy these cycles disappeared. 


\section{REFERENCES} Boothby, W. M., Haines, S. F., and Pemberton, J. de J. (1931). Amer. J. med. Sci., 181,
81.

Carlson, A. J., and Jacobson, C. (1911). Amer. J. Physiol., 28, 133.

Horwitz, W. A., and Harris, M. M. (1936). Amer. J. Psychol., 92, 1403.

Howard, J. E., and Emerson, K. (In Press.)

Knospe, H. (1938). Mschr. Psychiat. Neurol., 99, 503.

Levine, M., and Richter, C. P. (1935). Arch. Neurol. Psychiat., Chicago, 33, 1078.

MacCallum, W. G., and Voegtlin, C. (1909). J. exp. Med., 11, 118.

McCullagh, E. P., and Kearns, J. E. (1935). Endocrinology, 19, 532.

Richter, C. P. (1927). Quart. Rev. Biol., 2, 307.

(1933). Endocrinology, 17, 73.

(1934). Arch. Neurol. Psychiat., Chicago, 31, 149. (1938). Ibid., 39, 587.

Richter, C. P., and Eckert, J. F. (1937). Endocrinology, 21, 50.

- (1939). Amer. J. med. Sci., 198, 9.

Wang, G. H. (1923). Comp. Psychol. Monogr., 2, 1.

Wilson, S. J. (1938). Arch. Surg., 37, 490. 